\title{
The Influence of Reference Practices on the Client-Librarian Relationship
}

\author{
Joan C. Durrance
}

\begin{abstract}
This paper raises questions about the influence of present reference practice on library user perceptions of the librarian as an information intermediary and on user ability to distinguish between librarians and other library staff. It discusses these questions within the context of the client-professional relationship, using data from a study of the users of three university libraries in the Midwest. The author concludes that present reference practice hinders the development of a true client-professional relationship.
\end{abstract}

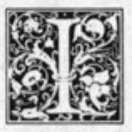

$\mathrm{n}$ a recent editorial in College $\mathcal{E}$ Research Libraries, writing in the context of evaluation of reference performance, Charles Martell raised a number of important questions; one of them was "How does the environment in which we work discourage ... [the] assessment [of reference performance]?"'1 Questions like this, which call for an examination of the basic reference model, have seldom been asked by librarians and researchers and certainly have not been answered by them. ${ }^{2}$ One study that raises a similar question, "What effect does the environment of reference service have on the reference interview?" was done by Mary Jo Lynch. She sketched the differences between our professional model and other models:

Other professionals do not usually operate in such an atmosphere. Clients commonly make appointments to see them and even when appointments are not made the professional works in a private or semiprivate place and admits clients one at a time. Reference librarians, by contrast, wait in a public place for any client that may come along. ... The implications of this situation must be taken into account in any consideration of the reference interview. ${ }^{3}$
Although her study found that library users are not well served by the public practice of reference she suggested that it "may be necessary because ... of the way that people use libraries. ${ }^{14}$ I would argue that people use libraries the way they do because they are encouraged to do so by the environment created by librarians.

This paper attempts to apply empirical data to the concerns that Martell, Lynch, and others have raised. It addresses these concerns by breaking them into several component questions: (1) Does present practice limit the ability of library users to distinguish between librarians and other staff members? (2) Does it make it difficult for library users to see librarians as information intermediaries? (3) Does present practice discourage library users from becoming clients of librarians? (4) Does it make it difficult for librarians to function as professionals?

This paper addresses these questions within the framework of two concerns that have reappeared with disturbing regularity in the literature of librarianship. The first is the problem of librarianship as a profession, in particular the image that

Joan C. Durrance is assistant professor at the School of Library Science, University of Michigan, Ann Arbor, Michigan 48109. 
the public has of librarianship as a profession. ${ }^{6}$ The second concern is a component of the first: librarianships's inability to develop an adequate theoretical framework. In a recent paper on professional issues, Michael Winter noted that "the lack of an adequate theoretical body of knowledge is a serious obstacle to the professional development of an occupation. ${ }^{\prime \prime 7}$ Winter goes on to say:

The various dimensions of professionalization are interdependent. Thus problems in the knowledge base, combined as they are with low public recognition and complicated by structural constraint, are probably more serious in librarianship than the same problems are in other disciplines. ${ }^{8}$

A better understanding of the effect of the reference environment on the user will add to the theoretical base required for optimum practice of reference. In addition, it will make it easier for librarians to communicate more clearly their role to the public and should permit the field to evaluate reference performance more effectively. The literature devoted to the evaluation of reference service is both extensive and inadequate, perhaps because it does not adequately analyze the limitations of present practice. ${ }^{9}$

In a 1983 review article on reference theory Richard Danner found that "despite continuing interest in the problem of reference theory. . . librarians have been unable to reach a consensus on a definition of library service or on a characterization of the activity." ${ }^{10}$ Thelma Friedes reached a similar conclusion in her review of trends in academic libraries. ${ }^{11}$ Danner posits that the articulation of a theory of reference service is "of crucial importance to the future of the profession" in light of current trends in the development of information technology. ${ }^{12}$ Although for more than a decade researchers have examined the interaction that occurs between the librarian and the library user in the reference transaction, the affect of present identification practices on the professional-client relationship, per se, has not been adequately examined. ${ }^{13}$ Communication concepts such as the reference interview have been defined and explained within the context of present professional practice, but without discussion of the effect that present practice might have on the library user. ${ }^{14}$

Librarians have assumed that the distinctions necessary to distinguish between them and other staff can be made by library users. Yet, a quarter of a century ago, William Goode reported that the public's perception of librarians as clerks posed a serious problem for librarianship as it sought professional status. ${ }^{15}$ In 1977 , Peter Hernon and Maureen Pastine found that "students perceive the role of librarians, clericals, and student assistants as being the same." 16 They also found that although 87 percent of the university students in their study thought that librarians and other library staff members differed in their backgrounds, most students believed that librarians sat behind desks, and were older, more knowledgeable and competent than other staff. ${ }^{17}$

The present study examines the perceptions that library users have about library practitioners and the effect these perceptions have on their behavior both as library users and as clients.

\section{THE CLIENT PROFESSIONAL RELATIONSHIP IN REFERENCE}

The perceptions library users have about the library practitioner will influence the nature of the professional-client relationship that they develop. If a norm for the professional-client relationship has been developed and transmitted to library users, it is that the user should approach an anonymous staff member of unknown credentials who is behind one of several public desks and who is often simultaneously engaged in some other activity. Since these unidentified, uncredentialed staff members rotate days and times, the library user is required to initiate contact with any one of several desk staff. If the user is referred to another source of information, the referral is likely to be to another location and not to a staff member. Most academic libraries adhere to this pattern.

Certain conditions must be present before a client engages a practitioner in a professional relationship. It is the argument of this paper that the traditional practice of reference may transmit indistinct messages to library users about the role and practice of librarianship, making 
it difficult for library users to become clients of librarians. The paper asks the question "Does this practice produce a set of conditions conducive to the development of a true client-professional relationship?"

\section{Method}

Major variables in this study include: (1) user knowledge of staff differentiation, (2) user ability to recognize specific staff members, (3) the inclination of users to look for and return to particular staff members, (4) the inclination to avoid specific staff members, and (5) the criteria that are used as the basis for a decision to return to or avoid a staff member.

This study was conducted with users of three academic libraries that are similar in size and user composition: The Eastern Michigan University $(18,880)$, Bowling Green State University $(16,866)$, and the University of Toledo $(21,489)$. Since there were no major differences in responses among the three universities, the data from all sites were combined. Interviews were conducted with 429 library users as they left each library during morning, afternoon, evening, and weekend hours for the months of May and June 1984.

Interviewers were stationed inside near the exit gates. With the exception of the principal investigator, interviewers were University of Michigan graduate students in library science and political science; both male and female interviewers were used. Eight two-hour blocks were spent interviewing at each site by a rotating team of two; an average of thirty-two hours was spent on interviews at each institution. Based on use data provided by staff at these institutions, interview hours were weighted toward more heavily used afternoon and evening hours. Each interview took between two and seven minutes.

The interview elicited detailed information from the user about a recently asked reference question. This question was used as a critical incident around which the interview was structured. To distinguish between a reference and a directional question, and to establish a reasonably time frame, the interviewer inquired if the user had asked a library staff member for assistance in getting information about a topic or help in locating library materials within the six past months. Each library user was placed into one of three categories by type of assistance sought: reference question, (including title-author questions), directional-equipment request, or no question.

\section{USER KNOWLEDGE OF STAFF DIFFERENTIATION}

Does present practice make it difficult for library users to identify librarians? This question was tested by analyzing three related factors: (a) the extent to which library users were aware of staff differentiation; (b) the categories assigned to library staff members by interviewees, coupled with the degree of uncertainty expressed; and (c) the reasons given for indicating that a staff member was a librarian, a library assistant, or a student assistant. Although nearly 84 percent of the users were aware that several categories of library staff work in academic libraries (a finding similar to Hernon and Pastine), they were not always able to identify professional staff.

When all library users who knew that different categories of staff worked in libraries and who had requested assistance were asked to indicate the category to which they would assign the staff member who had assisted them, the certainty dropped from 84 percent who knew that different categories of staff work in libraries to 62 percent who were sure of the category of the person who had assisted them. Over one-third were uncertain about the category.

\section{The Ability to Identify Library Staff Members by Name}

In most professions, those who interact directly with the client are known by name. Seventeen percent of the users who asked questions knew the staff members by name. Those who recognized or knew the name were likely to be more intensive library users than those who did not. They were more likely to report that they typically used several types of materials. They were twice as likely to report regularly seeking assistance than those who didn't know the name of the staff member (19.2 percent to 10.1 percent). Finally, they 
were far more likely to return to the staff member they consulted ( 74 percent) than those who didn't recognize or know the name of a staff member (47.9 percent).

A 1980 study of citizen-group leaders showed that if they knew the name of a library staff member, they were likely to have a higher library success rate. ${ }^{18}$ However, the present study showed that recognition of a staff member or knowledge of the name did not assure that the library user knew the category to which the staff member belonged. Nearly a third of the respondents who could recognize or name a staff member were not sure to which category he or she should be assigned (see table 1).

\section{Rationale for Selecting Specific Staff Categories}

The reasons given by the 256 library users who were sure of the staff member's status fell into five categories: (1) appearance and environmental clues, (2) expertise, (3) bibliographic instruction or some other practice that facilitated identification, (4) personal knowledge and, (5) "no reason" or "don't know" (see table 2).

The reasons are strong indicators that users are unsure how to differentiate between librarians and other staff members. The evidence suggests that the knowledge users have about how to identify the different categories of staff is based not on information, instruction, or other assistance, but on appearance and supposition.

\section{Appearance and Environmental Clues}

Over half of the users who asked a reference question relied on clues provided either by the environment or by the staff member's appearance to make a decision on staff category. Librarians were identified primarily as older and as behind

TABLE 1

CATEGORIES ASSIGNED TO LIBRARY STAFF MEMBERS BY THOSE WHO HAD ASKED FOR ASSISTANCE

\begin{tabular}{lrr}
\hline \hline Category & Number & Percentage \\
\hline Librarian & 115 & 37.8 \\
Librarian, not sure* & 36 & 11.8 \\
Library assistant & 28 & 9.2 \\
Library assistant, not sure* & 15 & 4.9 \\
Student assistant & 47 & 15.4 \\
Student assistant, not sure* & 11 & 3.6 \\
Other/Don't know & 50 & 16.4 \\
Totals & 302 & 100.0 \\
\hline
\end{tabular}

"Respondent indicated the category with hesitation, i.e., "I think she must have been a librarian," or, "T'm pretty sure he's a student."

TABLE 2

REASONS GIVEN FOR ASSUMING

THAT A STAFF MEMBER SHOULD BE ASSIGNED TO A PARTICULAR CATEGORY

\begin{tabular}{|c|c|c|c|c|c|c|c|}
\hline \multirow[b]{2}{*}{ Reason Given } & \multicolumn{2}{|c|}{ Librarian } & \multicolumn{2}{|c|}{ Category Selected } & \multicolumn{2}{|c|}{ Student } & \multirow[t]{2}{*}{ Totals } \\
\hline & $\mathrm{N}$ & $\%$ & $\mathrm{~N}$ & & $\mathrm{~N}$ & $\%$ & \\
\hline Appearance & 80 & $58.8 \%$ & 20 & $14.7 \%$ & 36 & $26.5 \%$ & $=136(100 \%)$ \\
\hline Expertise & 61 & $89.7 \%$ & 6 & $8.8 \%$ & 1 & $1.5 \%$ & $=68(100 \%)$ \\
\hline ID Practice & 15 & $62.5 \%$ & 5 & $20.8 \%$ & 4 & $16.7 \%$ & $=24(100 \%)$ \\
\hline Bib. Inst. & 10 & $100 \%$ & 0 & & 0 & & $=10(100 \%)$ \\
\hline Knew Before & 9 & $39.1 \%$ & 4 & $17.4 \%$ & 10 & $43.4 \%$ & $=23(100 \%)$ \\
\hline No Reason & 12 & $38.7 \%$ & 7 & $22.6 \%$ & 12 & $38.7 \%$ & $=31(100 \%)$ \\
\hline
\end{tabular}

Note: All reasons given by respondents were recorded. Some respondents gave more than one reason for assigning a staff member to a particular category. This table is a combination of six cross-tabulations (one for each reason given). 
desks. Most younger staff were assigned to the student category. Users generally relied on appearance and location rather than on any other method for determining the categories to which a staff member was assigned.

\section{Expertise}

Expertise was associated almost exclusively with the librarian category. However, it is interesting to note that although sixty-eight (27 percent) of the respondents recognized expertise as a reason for assigning a staff member to a category, library users cited appearance twice as often (168 responses). Although appearance and environmental clues are only circumstantial evidence, they are the most common means used to determine professional status.

\section{Personal Knowledge}

Twenty-three users said that they were sure of the category of the staff member who assisted them because they knew the person outside of the library. Nearly half were fellow students; the others were known in another context. The categories assigned to staff by those who are acquainted with one another are more likely to be accurate than the categories assigned based on appearance or expertise.

\section{Bibliographic Instruction and Other Practices That May Result in Staff Identification}

Only thirty-five users based their rationale on what appears to be a fairly accurate method to identify library staff categories-previous contact through bibliographic instruction (BI) or other practices used by librarians, which may result in more accurate identification of credentials and/or status. The other identification practices include self-identification by or referral to another staff member by name. These factors were mostly used to place the staff in the librarian category. All ten users who noted that the staff member had spoken to a class placed the staff member in the librarian category.

\section{No Reason}

Finally, thirty-one library users said that they did not know and/or had no reason to think that the staff member belonged to the specific category to which they had been assigned.

The first part of this paper has shown that present practice makes it difficult for library users to distinguish librarians from other library employees. It must be recalled that users were asked these questions not about any staff, but about library staff who had answered reference questions. Overall, these data show that although library users may be aware that there is staff differentiation in libraries, they are not able to distinguish with any certainty between librarians and other library employees when asking for assistance in obtaining information or materials.

The final portion of this paper returns to the questions and concerns raised in its opening paragraphs. Does present practice make it difficult for library users to perceive librarians as information intermediaries? Does it discourage most library users from becoming "clients" of these information intermediaries? Does it make it difficult for librarians to function as professionals? The final portion will discuss different modes of client behavior that result from the present anonymous practice of reference. It will examine the differences among four types of library usersthose who do not seek assistance, those who ask only directional questions, those who seek assistance from library staff members, and those who not only seek assistance but also look for particular staff members when they need help.

\section{INCLINATION OF THE USER TO SEEK ASSISTANCE}

Given the anonymous practice of reference at an open desk, any relationship developed by the user and the practitioner is likely to be shaped by the user. Several variables may lead the user to recognize that a staff member may function as an information intermediary, e.g., the inclination of the user to seek assistance. Figure 1 outlines possible client-professional relationships; table 3 shows the number of users who asked a question in each category and the recency of these questions. 
FACTOR

\begin{tabular}{|c|c|c|}
\hline & Asks No Questions & Asks Only Directional Question \\
\hline $\begin{array}{l}\text { Library Use } \\
\text { (Building/Materials) } \\
\text { Patterns }\end{array}$ & $\begin{array}{l}\text { Building use only; } \\
\text { Building use and } \\
\text { materials use }\end{array}$ & $\begin{array}{l}\text { Building use only; } \\
\text { Materials use }\end{array}$ \\
\hline Recognition Factor & Not known & $\begin{array}{l}\text { No indication of staff } \\
\text { recognition }\end{array}$ \\
\hline $\begin{array}{l}\text { Intermediary Use } \\
\text { Pattern }\end{array}$ & No questions & $\begin{array}{l}\text { Asks directional } \\
\text { questions }\end{array}$ \\
\hline Preference Factor & Not applicable & Goes to anyone \\
\hline Inclination to Return & Not applicable & $\begin{array}{l}\text { Either return or no } \\
\text { preference }\end{array}$ \\
\hline $\begin{array}{l}\text { Client-determined } \\
\text { Relationship }\end{array}$ & No contact & $\begin{array}{l}\text { Relationship limited to } \\
\text { single inquiry; Not } \\
\text { professional in nature }\end{array}$ \\
\hline Type of Relationship & No relationship & $\begin{array}{l}\text { Relationship not } \\
\text { professional }\end{array}$ \\
\hline
\end{tabular}

TYPES OF QUESTIONS ASKED

Asks Reference Questions

Building use; Materials use

No indication of staff recognition

Asks directional questions; Asks reference questions of any staff

Goes to anyone

May return

Relationship limited to single question

Aware of intervention capability of library staff
Building use; Materials use

User reports recognizing staff; Recognizes only or knows name

Asks directional questions; Asks reference questions of any staff, but may also seek particular staff Inclined to look for particular staff; May avoid specific staff

More likely to return

Prefers particular practitioners; Relationships extend over time

True client-professional relationship 
TABLE 3

TYPES OF QUESTIONS ASKED IN THE PAST SIX MONTHS

\begin{tabular}{lcccc}
\hline \hline & None & \multicolumn{3}{c}{ Type of Question } \\
Recency of Question & $\begin{array}{c}\text { Directional } \\
\%\end{array}$ & $\begin{array}{c}\text { Title/ Au. } \\
\%\end{array}$ & $\begin{array}{c}\text { Reference } \\
\%\end{array}$ \\
\hline Day of the Interview & 0 & $23 \%$ & $26 \%$ & $24 \%$ \\
Less than 2 Weeks & 0 & 31 & 30 & 35 \\
2 Weeks to 1 Mo. & 0 & 17 & 15 & 9 \\
1-3 Months & 0 & 18 & 21 & 27 \\
4-6 Months & 0 & 11 & 9 & 6 \\
Over 6 Months or None & $\%$ & $100 \%$ & $100 \%$ & $100 \%$ \\
Total N $=426 \quad \mathrm{~N}=$ & 71 & 83 & 110 & 162 \\
\hline
\end{tabular}

\section{Users Who Do Not Seek Assistance}

Seventeen percent of the users in the sample made no contact with a library staff member within the six months prior to the study. Yet over half of them used the library several times a week. Half reported using the library as a place to study and three-fourths reported using library materials regularly. The fact that these users had made no contact with library staff but reported heavy building and materials use is an indicator that they perceive the library as a useful building. But either they do not recognize that staff may function as information intermediaries or they have no need to interact with the staff.

2. Users Who Ask Only Directional or Equipment Related Questions

Nearly one in five users had asked only directional questions. Sixty-five percent reported that their typical library use included facility use e.g., computer terminals and study tables. The majority were frequent users; nearly 58 percent reported using the library several times a week. Sixty-six percent reported using the library as a place to study on the day of the interview and about half reported using library materials regularly. ${ }^{19}$

These users expressed greater uncertainty about the different categories of staff in libraries than other users; 22 percent were not aware of staff differentiation in libraries. When users who asked directional questions are combined with those who asked no questions, the study shows that one-third of the users had not asked any questions that required the assistance of a librarian.

Users who asked directional questions differed from users who asked no ques- tions in that they were inclined to seek, but had not made use of the professional skills of librarians. A number of studies have raised questions about those who use libraries but do not call on the professional capabilities of librarians. ${ }^{20}$ This study compares the behavior of those who are inclined to see librarians as intermediaries with those who do not.

3. Users Who See Library Staff as Intermediaries

The inclination to view the library staff member as an intermediary is a prerequisite for the development of a professional relationship. Nearly two-thirds of the users questioned, or 275 persons, had sought assistance. These users can be divided further into two distinct but disproportionately sized groups. The vast majority of those who asked questions ( 85 percent) said that they would go to any staff member when they had a question. The remaining 15 percent preferred to look for particular staff members. The principal differences between these two groups will be discussed below.

a. Users Who Go To Any Staff Member

Those who ask questions but who do not look for particular library staff members represent the largest category of library users. These individuals conform to the client norm expected by present reference practice. Nearly 62 percent reported using the library several times a week. Their library materials and building use was similar to those who asked no questions or who asked only directional questions. About two-thirds had used the library as a place to read or study on the day of the interview. Only 13 percent reported seeking assistance regularly. These users 
ask questions but do not seek out particular staff. Although they did not customarily look for particular staff members, 55 percent said they would return to the person who had assisted them if help was needed at another time. Findings show that this large group does not engage in a true client relationship. Their contact with librarians as information intermediaries is likely to be limited to single, isolated encounters.

b. Users Who Act as Clients-Those Who Seek Out Particular Staff Members

All library users were asked, "When you use this library do you usually look for particular people when you need assistance?" Only 10 percent of all users look for particular staff. The library-use patterns of this minority follow: their frequency of use and library building and materials use patterns are not substantially different from the patterns shown by other users; less than 19 percent reported seeking assistance during their typical use patterns. It is not surprising to find that these and all other library users in this study report heavy materials and building use and minimal assistance seeking; library users spend far less time as clients than as library users. However, those who have recognized the value of the intermediary role do use the professional expertise of librarians. The next section of this paper examines the client behavior of these individuals.

\section{The Client Mode-the Inclination to Look for Particular Staff}

The 15 percent of users who looked for particular staff members were far less likely to say they were unsure of the category of the staff member ( 16.3 percent) than those who did not look for particular staff ( 33.7 percent). In addition, they were more likely to say that they selected a staff member on the basis of expertise (26.8 percent) than those who did not look for a particular staff member (20.9 percent). They were much less likely to say that they would go to whomever was at the desk (14.6 percent) than those with no preference (27.4 percent). Library users who looked for particular staff members were also much more likely to say that they avoided certain staff members ( 22 percent) than those who did not. (8.6 percent).

Individuals who look for particular staff when they seek assistance act like the clients of other professionals. They select the professional and return to him or her when they need assistance. They do not prefer to go to just anyone. In the process of selecting, they may also make a conscious decision to avoid a particular practitioner. They may learn the name of the staff member with whom they have developed a relationship, but if not, they will return to the staff member through recognition alone. Users who have learned the name of a practitioner benefit by having the ability to reestablish communication with a professional at a later time. ${ }^{21}$

\section{Criteria Used to Select the Library/Information Professional}

Only those users who have engaged in client behavior develop criteria to select staff. They constitute a small minority of library users; in this study only forty-one qualified. In librarianship the absence of obvious credentials or specialties known to the client-such as family practice or obstetrics in medicine, or divorce or taxation in law-requires the clients to develop their own criteria.

These criteria allow the client to develop the qualities later sought in the practitioner. Expertise was the criterion most often used by the respondents in this study; half of those who looked for a particular staff member said that the staff member was selected for expertise or knowledge exhibited in a past encounter. Thirty-nine percent of those who looked for a particular staff member said that they selected the staff member because they recognized that person. Finally, sixteen did so because the staff member seemed friendly or approachable.

\section{The Inclination to Return}

The inclination to return is a strong indicator that the user has established a client relationship with a staff member. In this study, the 360 users who asked questions, and would return to the staff member who had assisted them, were more likely to know that different categories of staff 
worked in the library ( 89 percent) than those who didn't care if they returned to the staff member (79 percent). They are more than twice as likely to recognize or know the name of the staff member (26 percent) than those who didn't care (13 percent). None of those who said they would prefer to go to someone else the next time knew the name of the staff member who had assisted them. Those who return are twice as likely to say that a library staff member had spoken to their class (12 percent) than those who had no preference ( 6 percent). Finally, they are twice as likely to cite expertise as a criterion for selection than those who had no preference ( 25 percent to 12 percent).

\section{Criteria Used to Avoid Staff}

Library users who avoid particular staff members have client behavior in common with those who seek out staff. They distinguish among staff members and they exhibit preferences. Fourteen percent of those who asked questions reported that they avoided specific staff members. Library users who sought specific staff members were more likely to avoid particular staff ( 22 percent) than those who did not (9 percent).

The reasons for avoidance were grouped into two main categories: (1) negative style of the staff member, based on past experience or perception; and (2) past experience unrelated to expertise. About half of the users avoided particular staff members because they were unpleasant to approach. Although some users avoided a particular staff member because they thought that person was a student or a nonprofessional, 56 percent of the staff members avoided were thought to be librarians. Forty-four percent avoided certain staff members because in a past experience the staff member had appeared to be too busy to deal with their inquiry, had given no help, or had given more help than the user needed.

\section{Summary and Implications}

The introductory section of this paper raised questions about how present reference practices keep users from recognizing the professionalism inherent in this ac- tivity. The data show that library users: (1) do not easily distinguish between librarians and other staff members; (2) have only a vague notion of staff differentiation; (3) are unaware of the credentials of librarians; and (4) environmental clues or other circumstantial evidence are used to identify staff by category.

Without doubt, misperceptions influence the ability of librarians to practice their profession, because librarians cannot serve effectively those who understand neither their purpose nor their expertise. If users cannot distinguish between professionals and other staff, they may respond inappropriately to the profession. Inappropriate responses may include (1) a misunderstanding of the role of the librarians as an information intermediary, (2) assuming all staff have the same credentials and provide the same level of service, (3) developing invalid criteria about whom to consult when assistance is needed, or (4) thinking of staff as merely custodians of material. Professional practice that places anonymous staff members behind the reference desk not only lacks a theoretical basis but also is dysfunctional. ${ }^{22}$

Present practice produces users who have little contact with librarians, usually ask only directional questions, and show little preference for who answers their questions. Most users are not true clients: their relationship is limited by present reference practice to an isolated encounter. A few users have overcome the constraints of the environment and developed a true client relationship with willing professionals or other staff.

In recent years libraries have made greater use of information desks to respond to the directional questions that make up such a large percentage of the reference work load. These desks have been staffed by nonprofessionals or students trained to answer directional questions, to provide simple bibliographic information, and to filter questions. ${ }^{23}$ It does not appear that those who have created these desks have taken into account the limited knowledge that library users have of staff differentiation in libraries. (This statement is equally true of the presently configured reference desk.) 
The information desk has great potential as a cost-effective method for providing directional information and for referring true reference inquiries to the professional staff member with the appropriate credentials at a time that is convenient for both the user and the librarian. Libraries need to experiment with models that underscore the professional functions of librarians and staff differentiation in libraries.

Altering the present reference configuration to make it more client-centered or user friendly is not a task to be undertaken lightly. Charles Martell, who recommends a total restructuring of the academic library from its traditional functional design-acquisitions, cataloging, circulation, and reference - to a number of client-centered functional work groups, believes that a new client-centered approach would require two to five years in the prototype development stage before the model could be evaluated. ${ }^{24}$ However, prior to implementing a reformed model of client-centered reference practice, planners should consider research findings that will promote the development of a true client-professional relationship. Librarians who devise client-centered models need to examine the messages currently sent to library users by existing reference and other public service desk policies and practices.

A reconfigured reference service should exploit the benefits brought to the clientprofessional relationship by welldesigned bibliographic instruction, online searching, faculty liaison, and other practices that highlight the expertise of librarians. It should eliminate aspects of present reference practice that confuse the public. In all likelihood, a client-centered reference model will effectively use nonprofessionals just as other professions effectively use auxiliary staff. A reconfiguration may include the provision of various physical changes in the library building and in services, e.g., clearly visible private or semiprivate offices for professional staff, methods for identifying information intermediaries by name and general area of expertise. It might also include methods that will help the user become a client and facilitate the client's ability to find the right intermediary. Such a reconfiguration should provide the basis for more accurate assessment of reference performance.

\section{REFERENCES AND NOTES}

1. Charles Martell, "Editorial: Performance at the Reference Desk," College \& Research Libraries 46:4 (Jan. 1985).

2. See Charles A. Bunge, "Interpersonal Dimensions of the Reference Interview: A Historical Review of the Literature," Drexel Library Quarterly 20:4-23 (Spring 1984).

3. Mary Jo Lynch, "Reference Interviews in Public Libraries," Library Quarterly 48:136 (April 1978).

4. Ibid.

5. A number of questions about the professional aspects of reference are raised in Mary Biggs and others, "Replacing the Fast Fact Drop-In with Gourmet Information Service: A Symposium," Journal of Academic Librarianship 2:68-78 (May 1985).

6. For a discussion of the issue, see Michael F. Winter, "The Professionalization of Librarianship." Occasional Papers no.160 (Urbana: University of Illinois, Graduate School of Library and Information Science, July 1983).

7. Ibid., p.36.

8. Ibid., p.37.

9. For a critical review of the evaluation of reference services, see Ellen Altman, "Assessment of Reference Service," in The Service Imperative: Essays in Honor of Margaret E. Monroe, ed. Gail A. Schlachter (Littleton, Colo.: Libraries Unlimited, 1982), p. 169-85.

10. Richard A. Danner, "Reference Theory and the Future of Legal Reference Service," Law Library Journal 76:217 (Spring 1983).

11. Thelma Friedes, "Current Trends in Academic Libraries," Library Trends 31:457-74 (Winter 1983). Theme issue, entitled "Current Trends in Reference Services."

12. Danner, p.218. 
13. See Mary Ann Swope and Jeffery Katzer, "The Silent Majority: Why Don't They Ask Questions?" $R Q$ 12:161-66 (Winter 1972); see Bunge for a review of the literature.

14. Social psychologist Erving Goffman has examined a number of social interactions from the perspective of their affect on the individual. In particular, see chapter 4 of Relations in Public (New York: Harper, 1971).

15. William J. Goode, "The Librarian: From Occupation to Profession?" Library Quarterly 31:313 (Oct. 1961).

16. Peter Hernon and Maureen Pastine, "Student Perceptions of Academic Librarians," College \& Research Libraries 38:132 (Mar. 1977).

17. Ibid.

18. Joan C. Durrance, "The Generic Librarian: Anonymity Versus Accountability," RQ 22:278-83 (Spring 1983).

19. Paul Kantor's studies show that, normally, only 20 to 25 percent of academic library users are reading library materials at any given time. (Interview with Paul Kantor, President of Tanatalus, Oct. 10, 1985.)

20. In particular, see Swope and Katzer, Hernon and Pastine.

21. Joan C. Durrance, "Citizen Groups and the Transfer of Information in a Community" (Ph.D. Diss., University of Michigan, 1980), p.170-74.

22. Several authors have called attention to the dysfunctional nature of presently configured reference from the perspective of the user; see Lynch, Swope and Katzer, Hernon and Pastine, and Friedes. The findings of Haack and others suggest that the reference environment contributes to burnout. Mary Haack and others, "Occupational Burnout Among Librarians," Drexel Library Quarterly 20:46-72 (Spring 1984).

23. See Martin P. Courtois and Lori A. Goetsch, "Use of Nonprofessionals at Reference Desks," College \& Research Libraries 45:385-91 (Sept. 1984); Egill A. Halldorsson and Marjorie E. Murfin, "The Performance of Professionals and Nonprofessionals in the Reference Interview." College \& Research Libraries 38:385-95 (Sept. 1977); Laura M. Boyer and William C. Theimer, Jr., "The Use and Training of Nonprofessional Personnel at Reference Desks in Selected College and University Libraries," College \& Research Libraries 36:193-200 (May 1975).

24. Charles R. Martell, The Client-Centered Academic Library: An Organizational Model (Westport, Conn.: Greenwood, 1983), p.102. 